\title{
Social Peace and Political Pluralism
}

\author{
Vereno Brugiatelli ${ }^{1, a}$ \\ 1Department of Philosophy, Education, and Psychology, University of Verona, Italy \\ àverenob@libero.it
}

\begin{abstract}
Keywords: Recognition, Capabilities, Political Pluralism, Public Debate, Practical Wisdom, Social Peace.
\end{abstract}

\begin{abstract}
In the modern age cultural and political pluralism received the serious consideration of the Enlightenment philosophers. In the contemporary age, it is the centre of attention of several thinkers who tackle the often dramatic problems related to the misrecognition of rights and freedoms in cultural minority groups. Liberalism in its multiple formulations puts the universal principles that ignore differences at the base of its reflections. Philosophers such as Charles Taylor and Michael Walzer often insisted on the political necessity to face the problem of differences, denouncing the historical and cultural limits of the different forms of liberal universalism. By examining the juxtaposition between universalism and communitarism, in this paper I intend to analyse the conflicting aspects of this contrast to obtain the emergence of viewpoints to overcome such conflicts. I will base my analysis on the resources of the recognition of the rights to capabilities, public debate and practical wisdom.
\end{abstract}

\section{Capabilities and social justice}

Undeniably, cultural minorities are a real political urgency in liberal societies [1]. We need to work to build political pluralism that is able to guarantee all social groups the equal right to preserve their cultural traditions and the equal right to freedoms. M. Walzer has pointed out that democracy plays a fundamental role in a plural society to ensure a political bond and reciprocity between individuals that do not share the same idea of good [2]. I believe that a pacific cohabitation between different social groups is impossible to obtain without guaranteeing them the recognition of the rights to act. In real political pluralism, institutions should favour the realization of such recognition as an intermediary for equal distribution. Amartya Sen and Martha Nussbaum elaborated a model of pacified living together and social justice that is exactly founded on the «agency» approach [3, 4]. Unlike Rawl's deontological and procedural approach, which is founded on the identification of equal institutions [5], Sen and Nussbaum's viewpoint starts from the real life of individuals, from the life that individuals are able - or unable - to live and from the actual capabilities they have. Society can give or deny the right to capabilities, accord or deny the freedoms to act and choose between different forms of life. Injustice exists when individuals are denied the recognition of capabilities, of freedoms that are indispensable to exert such capabilities [3]. The actual possibility of choice, i.e. freedom, appeals to «collective responsibility», that is «social responsibility». The latter is also responsible for the recognition of individual capabilities and substantial rights, or rights that can find a factual application in the daily life of people, in addition to being envisaged by the constitution.

\section{Misrecognition of rights and injustice}

An unequal distribution of agency and capabilities is often observed also in democratic societies. Such a different distribution of capabilities is evident also towards individuals that belong to cultural minority groups. The denial of power-capabilities to individuals who are not deprived of them gives origin to forms of misrecognition that involve alienation and degradation, not only at economic, but also ethic and cultural level. In fact, the different forms of misrecognition negatively affect the positive relationships that an individual can have with himself and with the world. As 
advocated by Axel Honneth, the denial of civil rights produces humiliation, the exclusion from participation in political life leads to frustration, and the feeling of exclusion derives from the denial of access to elementary goods [6]. Also Charles Taylor insists on the fact that different denials of recognition negatively affect the respect an individual can cultivate for himself. Misrecognition can produce severely disturbed affective conditions and negative feelings in the individual [7, 8]. In some instances, the psychical situations produced by misrecognition drive individuals to reaction and mobilization. Indignation, lived as an injury of personal respect, can prove so discouraging to degenerate into exasperation and violent anger. In other instances, however, it can constructively determine the willingness to become an actor in the fight for recognition, infuse determination and give a moral answer to offence [9].

\section{Culture of differences and politics of recognition}

Charles Taylor makes a reflection on the "politics of recognition" by taking into examination the discrimination produced by the "politics of equal recognition" - or "politics of equal dignity" which was developed during the 18th century and has been playing a fundamental role for approximately fifty years now. He observes that in the modern age, with the shift from honour to dignity, a politics of universalism has originated, which highlights the equal dignity of all citizens and has focused on the equalization of rights and titles. Nevertheless, such a universalism supported by the different forms of liberalism - has cancelled and neutralized the main differences in the cultures of the so-called minority or subordinate groups. The refusal to recognise the differences is translated into a misrecognition of the different identity of some cultural minorities.

Such misrecognition negatively affects the personal and collective identity, producing selfcontempt in the members of the offended groups. Hence the fight for recognition by minority communities, hence the creation of a "politics of difference". Taylor argues that the "politics of difference" has a universalistic base, which nevertheless differs from the politics of equality.

Whereas in the politics of equality equal dignity is affirmed as universal, together with a universal set of rights, the politics of difference requires the recognition of the unrepeatable identity of a specific individual or group, which differs from all other individuals [8]. For Taylor the politics of equality and universality represent the mask of a dominant particularism and culture. Consequently, liberalisms that affirm the equal dignity and the universal character of rights are merely an expression of the requirements of some particular dominant cultures. The politics of universality, according to Taylor, has often used equality to homogenize and frame individuals who belong to communities with different ethical values [1,8]. In this way, it has ended up harming the human dignity of many individuals.

As stated by Kant, human dignity resides in personal autonomy. Autonomy also consists in the person's capability of processing an idea of a good life. In order to respect human dignity, the liberal society must not impose its own idea of a good life. In Taylor's words, the dignity of a person is associated not only with a special conception of the good life - such that a person would impair their own dignity by departing from it - but with the power of considering and adopting a conception of their own. In view of the above, an equal society is a society that guarantees the freedom to adopt and pursue the individual's idea of good life. A liberal society is demonstrated by the way in which minorities are treated, including those who do not share the public definition of good, and especially by the rights accorded to each of its members [1].

\section{Limits of the politics of recognition and regulative universal}

In Taylor's politics of recognition Paul Ricoeur finds several positive aspects for the creation of a more equal society. He affirms that the problem of minorities is a real political urgency for liberal societies. Taylor's approach is inspired by pacification rather than conflict because it attributes higher importance to the request for recognition than to the claim for identity [9, 10]. For Ricoeur the claim for identity always has something violent with respect to others. On the contrary, the search for recognition implies reciprocity. According to Ricoeur, in the conflicts generated between 
the opposite necessities of universalism and the politics of differences, it is extremely useful to resort to practical judgement in situations (ethics of wisdom) in order to establish - even in a fragile vulnerable way - a mediation, a reflective balance between the need for universality and the recognition of its contextual limits [11]. Besides, referring to Habermas' discourse ethics [12] and to the transcendental approach derived from Kant, he affirms that it is not a question of renouncing the universal, but of contextualising it in the empirical. The universal is maintained as regulating idea and the latter can be assumed as the principle of the rules of compromise. An example of universal idea conceived in a regulative sense is found by Ricoeur in Kant's Perpetual peace. It is the idea of a "universal hospitality", which has the value of regulating universality. Being placed on a transcendental dimension, it opposes the idea - supported by communitarists - that starting from certain spaces of mutual recognition, a principle of political cohabitation may be generated [10].

Admitting Kant's position of the need to assume the universal only in a regulating sense, Ricoeur intends to go beyond the debate between universalists and communitarists.

\section{Respect for differences and integration politics}

In view of the above, I believe that for the respect for differences and social peace it would be useful to resort to the regulatory idea of "flexibility principle": all societies are characterised by major or minor conflicts and contradictions that cannot be solved in favour of either party. By ruling out rigid positions and decisions, solutions can be found - suggested by practical wisdom in a dynamic balance between the opposite parties. The politics of recognition stated by communitarists, such as Taylor's, can give rise to new claims for the onset of new collective identities claiming their differences. In this way, the collective identities in turn risk being further divided following the thrust of struggles for the recognition of new differences. In order not to follow such a drift, value must be given to diversity in order to make it interact in terms of dynamic vitality able to reinforce the capability to compromise. In this way it will be possible to create an elastic community in which cultural and ethnic diversities can co-exist, live together and co-operate, giving a peaceful solution to new problems. In the whirling fight to claim the differences, moving from a concept of universal in a regulatory sense may prove to give social weight to the binding values while guaranteeing the recognition of cultural differences. I believe that, in a multicultural community, the recognition of rights to capabilities can represent the base to devise a development plan - not only an economical and material plan, but also an ethical one - with a view to overcoming divisions and moving towards progressive integration. Although conflicts cannot be eliminated, they must occur and be regulated within democratic contexts through public debate, an exchange of opinions, as well as resolutions provided for by democratic principles and methods. In democracy, public reflection plays a central role in the realisation of a certain idea of social justice. Without a debate this idea can be extremely dangerous: it can become the mask of an ideology that, by deforming democratic life, breaks all dialogic relations and the debate between the rival parties is deprived of importance. As affirmed by Ricoeur, the ethics of practical wisdom provides for a concrete path to reach solutions that, in each individual case, can heal dangerous conflicts and enlighten the choice while respecting differences.

\section{References}

[1] Ch. Taylor: The politics of Recognition, first ed., Princeton University Press, Princeton NJ, (1992)

[2] M. Walzer: Sphères de justice, first ed., Seuil, Paris (1997)

[3] A. Sen, The Idea of Justice, first ed., Penguins Books Ld, UK (2009)

[4] M. C. Nussbaum: Creating Capabilities. The human development approach, first ed., Harvard University Press, Harvard (2011)

[5] J. Rawls: A Theory of Justice, first ed., Harvard University Press, Harvard (1971) 
[6] A. Honneth: Kampf um Anerkennung. Grammatik sozialer Konflikte, first ed., Suhrkamp Verlag, Frankfurt am Main (1992)

[7] A. Honneth: Verdinglichung, first ed., Suhrkamp Verlag, Frankfurt am Main (2005)

[8] Ch. Taylor: Sources of the Self. The Making of the Modern Identity, first ed., Harvard University Press, Cambridge MA (USA) (1989)

[9] P. Ricoeur: Parcours de la reconnaissance, first ed., Stock, Paris (2004)

[10] P. Ricoeur: La critique et la conviction, first ed., Calmann-Lévy, Paris (1995)

[11] P. Ricoeur: Le Juste 2, first ed., Édition Esprit, Paris (2001)

[12] J. Habermas: Moralbewusstsein und kommunikativen Handelns, first ed., Suhrkamp Verlag, Frankfurt am Main (1983) 